\title{
Anaphylaxis to Beluga caviar
}

\author{
Sébastien Lefèvre, ${ }^{1}$ Laurianne Moumane, ${ }^{2}$ Sandrine Jacquenet, ${ }^{3}$ Etienne Beaudouin ${ }^{1}$
}

\begin{abstract}
Fish roe is an extremely rare cause of anaphylaxis and although its consumption has increased in recent years. We described the case of a 59-year-old man, who experienced an anaphylactic reaction after consuming caviar. Skin prick-test were performed with Beluga caviar, salmon caviar, cod, salmon, hen egg yolk and egg white, ovalbumin, ovomucoid, shrimp and mold. Only SPT to Beluga caviar was positive. The absence of sensitization to fish and hen egg was confirmed by undetectable specific IgEs to cod, parvalbumin (Gad c 1 and Cyp c 1), egg yolk and egg white, ovalbumin and ovomucoid. An immunoblot was also performed and showed an IgE-reactive band indicated that the patient was sensitized to a $26 \mathrm{kDa}$ protein in Beluga caviar.
\end{abstract}

In the present case, immunoblotting of the patient's serum revealed a single IgE-reactive band at $26 \mathrm{kDa}$ band, which does not appear to correspond to the previous cases.

Key words: Anaphylaxis; caviar; food allergy; immunoblot; vitellogenin

\section{From:}

${ }^{1}$ Allergy department, Metz Regional Hospital, 1 allée du Château, 57530 Ars-Laquenexy, France

2 Allergy department, Besançon University Hospital, 3 boulevard Flemming, 25030 Besançon, France

${ }^{3}$ GENCLIS SA, 15 rue du Bois de la Champelle, 54500

Vandoeuvre-les-Nancy, France

\section{Introduction}

Fish roe is an extremely rare cause of anaphylaxis and although its consumption has increased in recent years, little has been published on allergic reactions to these caviar products. ${ }^{1-5}$ Beluga caviar is a luxury delicacy that is eaten as a garnish or spread. Only two cases of Beluga caviar-induced anaphylaxis have been reported in the literature. ${ }^{1}$ We report herein a new anaphylaxis case to Beluga caviar without allergies to other roes.

\section{Methods}

A 59-year-old man, with no atopic history, experienced an anaphylactic reaction after consuming caviar. Until now, he was accustomed to consuming caviar without reaction, once a year for Christmas. Ten minutes after the consumption of approximately one teaspoon of Beluga caviar without any other food or alcohol, he presented a severe anaphylactic reaction with hypotension $(60 / 40 \mathrm{mmHg})$ and dyspnea, requiring intramuscular epinephrine $(0.3 \mathrm{mg})$ in prehospital care enabling clinical improvement. Tryptase was sampled during the first hour after the onset of the anaphylactic reaction and showed an increase at $16.8 \mu \mathrm{g} / \mathrm{L}$. The basal tryptase rate was measured $24 \mathrm{~h}$ later at $5.6 \mu \mathrm{g} / \mathrm{L}$.

\section{Corresponding author:}

Sébastien Lefèvre

Allergy department, Metz Regional Hospital,

1 allée du Châteaux, 57530 Ars-Laquenexy, France

E-mail: s.lefevre@chr-metz-thionville.fr

IgE sensitization was investigated by skin prick tests (SPTs), specific IgE measurements (ImmunoCAP ${ }^{\circledR}$ Thermo Fisher Scientific, Wattham, USA) and immunoblotting. SPTs were performed with Beluga caviar (from sturgeon Petrossian, Paris, France), salmon caviar (Petrossian, Paris, France), cod, salmon, hen egg yolk and egg white.

\section{Results}

Only SPT to Beluga caviar was positive (wheal $15 \mathrm{~mm}$ ). In order to rule out irritation causing these results, the same tests were performed in 3 healthy volunteers. Positive controls were $10 \%$ histamine chlorhydrate $(7 \mathrm{~mm})$ and $9 \%$ codeine sulfate $(5$ $\mathrm{mm})$. Negative control was physiological serum (no reaction).

The absence of sensitization to fish and hen egg was confirmed by undetectable specific IgEs to cod, parvalbumin (Gad c 1 and Cyp c 1), egg yolk and egg white, ovalbumin and ovomucoid (ImmunoCAP ${ }^{\circledast}$ Thermo Fisher Scientific, Wattham, USA).

Since ImmunoCap ${ }^{\circledast}$ to Beluga caviar was not commercially available, specific IgEs were detected by immunoblot. Briefly, a protein extract from Beluga caviar was prepared and proteins separated by Sodium Dodecyl Sulfate (SDS)-PAGE, showing numerous proteins mainly around $25 \mathrm{kDa}$ as well as greater than $70 \mathrm{kDa}$. Separated proteins were then transferred onto a 
Polyvinylidene difluoride (PVDF) membrane and the immobilized proteins were incubated overnight at $+4^{\circ} \mathrm{C}$ with the patient's serum. After washing and incubation with an enzyme-labeled anti-human IgE antibody, the addition of enzyme substrate allowed detecting bands in the presence of specific IgEs in the patient's serum. The resulting IgE-reactive band indicated that the patient was sensitized to a $26 \mathrm{kDa}$ protein in Beluga caviar. A control immunoblot performed in the absence of the patient's serum did not show any nonspecific IgE reactive bands (Figure $\mathbf{1}$ ).
A.

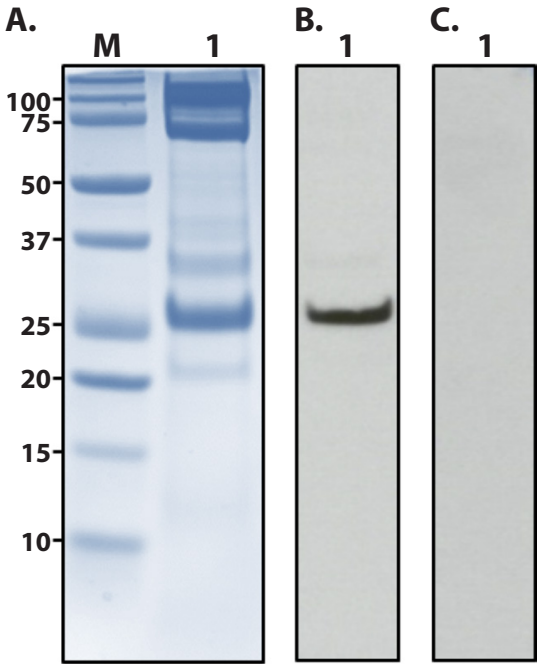

Figure 1. Coomassie blue-stained-SDS-PAGE with Beluga caviar (A) and corresponding IgE immunoblots with (B) or without $(C)$ patient's serum. Lane 1: Beluga caviar. M: molecular weight markers in $\mathrm{kDa}$.

\section{Discussion}

The main component in fish roe is yolk, the latter of which is comprised of 3 major proteins: lipovitellin $(21 \mathrm{kDa})$, phosvitin $(35 \mathrm{kDa})$ and $\beta^{\prime}$-component $\left.\left(\beta^{\prime}-\mathrm{c}, 18 \mathrm{kDa}\right)\right)$. These three proteins derived from the same precursor, vitellogenin, with an apparent molecular mass of $580 \mathrm{kDa}$, appear as two major bands corresponding to $180 \mathrm{kDa}$ and $120 \mathrm{kDa}$ after SDS-PAGE.,

Gonzalez-de-Olano et al. have identified several proteins in salmon roe $(18$ and $21 \mathrm{kDa})$, trout roe $(18 \mathrm{kDa})$ and slated hake roe $(18$ and $30 \mathrm{kDa}){ }^{5}$

In their description of the first case of Russian Beluga caviar anaphylaxis, Untersmayr et al. performed an immunoblot with the patient's serum which revealed four unidentified IgE-reactive bands of $30,84,100$ and $118 \mathrm{kDa}$, the latter two being more reactive. ${ }^{1}$ In the reported case of Iranian Beluga caviar anaphylaxis, immunoblotting showed a broad spectrum of IgE-reactive bands ranging from 23 to $120 \mathrm{kDa}$, identified as fragments of vitellogenin by mass spectrometry. ${ }^{3}$ In the present case, immunoblotting of the patient's serum revealed a single IgE-reactive band at $26 \mathrm{kDa}$ band, which does not appear to correspond to the previous cases (Figure 1). Moreover, we can speculate that this protein is not a fragment of vitellogenin since another reactive band would likely have been found in this instance.

\section{Conclusion}

To the best of our knowledge, this is the first case of Beluga caviar anaphylaxis described in France. Our patient presented a selective food allergy to Beluga caviar. Both skin prick testing and immunoblotting pointed to an IgE-mediated reaction. The resulting sensitization appeared to be due to a $26 \mathrm{kDa}$ protein, which has not been described previously.

\section{Conflicts of interest}

- S Lefèvre, L Moumane and E Beaudouin: none

- S Jacquenet is employed by Genclis SA, a biotechnology company specialized in allergy

\section{References}

1. Untersmayr E, Focke M, Kinaciyan T, Poulsen LK, Boltz-Nitulescu G, Scheiner O, et al. Anaphylaxis to Russian Beluga caviar. J Allergy Clin Immunol.2002;109:1034-5.

2. Flais MJ, Kim SS, Harris KE, Greenberger PA. Salmon caviar-induced anaphylactic shock. Allergy Asthma Proc.2004;25:233-6.

3. Perez-Gordo M, Sanchez-Garcia S, Cases B, Pastor C, Vivanco F, Cuesta -Herranz J. Identification of vitellogenin as an allergen in Beluga caviar allergy. Allergy.2008;63:479-80.

4. Chen YH, Wu HJ, Tsai JJ, Lee MF. Anaphylactic shock caused by a $33-\mathrm{kDa}$ alpha S1-casein-like allergen in kingfish caviar. J Investig Allergol Clin Immunol. 2009;19:245-6.

5. González-De-Olano D, Rodríguez-Marco A, González-Mancebo E Gandolfo-Cano M, Meléndez-Baltanás A, Bartolomé B. Allergy to red caviar. J Investig Allergol Clin Immunol. 2011;21:493-4.

6. Bergink EW, Wallace RA. Precursor-product relationship between amphibian vitellogenin and the yolk proteins, lipovitellin and phosvitin. J Biol Chem. 1974;249:2897-903.

7. Hiramatsu N, Hiramatsu K, Hirano K, Hara A. Vitellogenin-derived yolk proteins in a hybrid sturgeon, bester (Huso huso $\mathrm{x}$ Acipencer ruthenus): identification, characterization and course of proteolysis during embryogenesis. Comp Biochem Physiol, Part A Mol Integr Physiol. 2002;131:429-41 